\title{
Proper name theory and implications for second language reading
}

\author{
Kimberly Klassen \\ International Christian University, Tokyo, Japan \\ Email: kimi.klassen@gmail.com
}

It is common currency among vocabulary researchers of English as a second language (L2) that L2 readers can identify and understand proper names in context (e.g. Hirsh \& Nation, 1992; Hu \& Nation, 2000; Nation, 2006; Webb \& Rodgers, 2009; Horst, 2013; Webb \& Macalister, 2013). A proper name is a word or groups of words used to refer to an individual person (actual or potential), place, or organisation; in English, proper names are marked by an initial capital letter (Proper noun, n.d.). It is assumed that the form (initial capital letter) and the function of the name (context) will signal to the reader that the item is a proper name (Hirsh \& Nation, 1992). On the surface, this seems like a reasonable assumption to make. Indeed, many L2 learners of English possess the declarative knowledge that English names of people, places, companies and products require an initial capital letter.

It has also been suggested that proper names will have been learnt in the first language (L1), and therefore can be treated as world knowledge (Hwang \& Nation, 1989). This assumption that proper names are low-burden items for L2 readers has led to a standard practice in L2 vocabulary research to treat proper names as known vocabulary (see Brown (2010) for an overview of proper name treatment in text coverage count research). More recently, some researchers have begun to eliminate proper names altogether from lexical analyses (e.g. Uden, Schmitt, \& Schmitt, 2014), a practice that seems to suggest that proper names play no role in reading comprehension.

Research is limited as to how L2 readers respond to proper names when reading continuous text, and it is not known if comprehension is adversely affected by unfamiliar proper names. Only one study (Kobeleva, 2012) (that this author is aware of) has looked at the effect of proper names on comprehension and that study looked at listening comprehension, not reading comprehension. Kobeleva (2012) compared L2 listening comprehension of news stories in two conditions, Names Known (i.e. pre-taught) and Names Unknown (i.e. unfamiliar). Detailed comprehension was better in the Names Known condition. Participants in the Names Unknown condition mistook proper names for common nouns. They also self-reported lower comprehension and rated the tasks as more difficult than participants in the Names Known condition. These findings indicate that proper names may have an effect on detailed comprehension and affective factors, and hence, there are possible implications for $\mathrm{L} 2$ reading as well.

\section{Proper names: Special kinds of words}

Both L1 and L2 reading research began to consider text difficulty with a focus on vocabulary around the late 1980s and early 1990s. While prior L1 readability indices had focused on factors of syllable, word and sentence length to determine text difficulty, this later research was less concerned with syntax and more focused on specific words found in a reading text. For example, L1 research (Carver, 1994) considered the ease or difficulty of reading texts in terms of the percentage of vocabulary known to the reader. Around the same time, L2 vocabulary researchers (e.g. Hwang \& Nation, 1989; Hirsh \& Nation, 1992) began to look at different types of reading texts and how learners 
might learn new vocabulary from such texts. Later, as computer-based language corpora became more widely available, researchers were able to make frequency counts of the vocabulary in texts. Computer programs like Range (Nation \& Heatley, 2002) were developed, whereby a vocabulary profile of a text could be generated. This profile shows which words in the text belong to the first band of 1,000 most common words $(1 \mathrm{~K})$, which belong to the second band of 1,000 most common thousand words $(2 \mathrm{~K})$, and so on. However, one problem for reading and vocabulary researchers was what to do with the proper names.

Proper names do not behave like other words. According to the lexicographer Patrick Hanks (2013), 'Proper names are special kinds of words, with special rules governing their role as conventional units of a language' (p. 64). Perhaps to the layperson, one obvious difference between proper names and other common words as units of language is that proper names are not usually included in dictionaries. Hanks (2013) notes that dictionaries that do not include proper names seem to operate on the assumption that words denote classes, not individuals; on the other hand, dictionaries that do include proper names seem to operate under the assumption that words include all items of culturally shared knowledge (p. 34). For example, Hanks (2013) remarks that if you do not know who Shakespeare was, then you are not a fully developed member of the English speaking community (p. 34). When considering how to handle proper names in their studies, researchers may have looked to dictionaries as authoritative sources on lexis for direction on how to treat proper names.

Given the lack of empirical support that proper names are low burden items for L2 readers, it can be helpful to consider different theoretical perspectives on proper names. Specifically, the aim of this paper is to consider the extent to which proper names may be part of an L2 reader's linguistic system; that is, whether proper names represent lexical or encyclopaedic knowledge. If proper names represent world knowledge, then one can assume proper names are known. Such a treatment of proper names follows the widely accepted philosophical view that proper names refer but do not have meaning (Lyons, 1977). However, if proper names represent lexical knowledge, the assumption cannot be made that the L2 reader will be familiar with all the proper names they encounter. This conceptualisation of proper names as lexis follows a view held by some linguists that proper names have categorical meaning, albeit minimal (Anderson, 2007; Van Langendonck, 2007). That is, proper names might consist of categorical meaning, such as gender or place, which an L2 reader might not be cognisant of. In that case, a reconsideration of how proper names are handled in L2 vocabulary and reading research would be warranted.

\section{Theoretical perspectives on proper names}

There has been much debate in both philosophy and linguistics concerning whether proper names belong to the language system, and whether they have meaning. This debate is reviewed here in consideration of whether proper names should be treated by researchers and teachers as part of an L2 reader's vocabulary knowledge or world knowledge. Because linguistic enquiry into proper names has been strongly informed by philosophical theorising, this review begins with the fundamental philosophical positions on proper names. Then, the contemporary linguistic debate surrounding proper names is reviewed in more detail. Finally, some perspectives on proper names from the field of lexicography are presented.

\section{Philosophical perspectives}

An early and significant philosophical position on proper names comes from John Stuart Mill (1865), who argued that while proper names denote, or refer to, an individual, they do not connote; that is, names do not indicate any attributes about their referents (p. 33). Lyons (1977) clarifies that Mill's use of the term 'connote' is philosophical, whereby connotation indicates the qualities of a thing. Mill (1865) used an analogy to illustrate how names are non-connotative: proper names are like the chalk marks put on houses by the robber in the Arabian Nights; while the mark serves a purpose to distinguish the houses, it does not have any meaning or say anything about the house (p. 36). 
Likewise, a proper name serves to distinguish but does not say anything about its referent. Thus, in the Millian perspective, proper names do not have meaning, as 'meaning resides not in what [names given to things] denote but in what they connote' (Mill, 1865, p. 36). That is, proper names can refer to (denote) entities, but they do not have meaning because they do not signify (connote) any features or qualities of those entities.

Gottlob Frege (1960) provided another influential position on proper names. He introduced the concept that in addition to reference, names have Sinn (sense). Lyons (1977) explains that how some philosophers use the term 'sense', others would say 'meaning'. For Van Langendonck (2007), Frege's Sinn is not the same as lexical meaning but could be understood as 'meaningfulness' (p. 27). In Frege's conception, expressions could have the same Bedeutung (reference) but not the same Sinn (sense). The example Frege used to illustrate this distinction was: The Morning Star is the Evening Star. These two names have the same reference (i.e. the planet Venus) but a different sense, or meaning.

It is from these two fundamental philosophical positions that the debate on proper names continues. In the Millian view, names refer to entities, but do not signify qualities of those entities. Because names do not have meaning (connotation), they are not part of language (Strawson, 1950). Conversely, under Frege's conception, names do have sense, or associative meaning, and should therefore be considered part of language. However, Lyons (1977) summarises the widely accepted philosophical view that 'proper names may have reference, but no sense, and that they cannot be used predicatively purely as names' (p. 219).

\section{Linguistic perspectives}

The philosophical debate on whether proper names have sense, or meaningfulness, is directly connected to the central issue of proper names in lexical analysis: whether names are an aspect of vocabulary or encyclopaedic knowledge, and the interrelationship between these two types of knowledge (Hanks, 2013). Linguists who take the Millian view of proper names argue that they have no lexical meaning, only encyclopaedic information. For example, Coates (2006) argues that proper names have no sense but he does not interpret this to mean that names are meaningless: the meaning is the referent (i.e. the person or object to which the name refers) (p. 365).

That names are observed to not be part of the linguistic system might be attributed to their minimal sense and the predominance of encyclopaedic information associated with them (Anderson, 2007, p. 158). Though he disagrees with this conception, Anderson (2007) attempts to describe this view of proper names: the lexical entry of a name, without the phonological and morphological information, consists of a concept of a referent. This concept provides access to encyclopaedic information that is particular to that referent, and the name is simply part of that concept; the concept is not part of the linguistic system (Anderson, 2007, p. 158). In other words, proper names can be thought of as 'memorized labels' for the entities they refer to (Allerton, 1987, p. 71), or like the robber's chalk marks, serving only to distinguish.

Under the Millian perspective then, when one fails to understand a proper name, it is assumed to be the result of a lack of world knowledge, not linguistic. In this regard, proper names seem to differ from other words: for if one fails to know a common word, this is attributed to a gap in linguistic knowledge, not world knowledge. However, Anderson (2007) gives two examples why this might not always be the case:

I nevertheless recognize as a language user that in English, for example, Elise is a name for women. And, on the other hand, we can also fail to grasp the denotation of common words on the basis of gaps in our knowledge of the world: for instance, I know that 'cantharides' is 'dried Spanish fly', but I would not be able to recognize a sample. (pp. 158-159)

In Anderson's example, the gender of Elise is linguistic knowledge while encyclopaedic knowledge about Elise would entail referent specific information, such as her job or character. Hence, there 
can be instances when knowledge of proper names can be of a linguistic nature, even though this information may be minimal.

The alternative linguistic view of proper names then is that they do have meaning. For linguists who assign proper names sense, or associative meaning, proper names are part of the linguistic system. Note, however, that Frege's 'sense' is interpreted somewhat differently among linguists. Allerton (1987) glosses 'sense' as 'language-internal semantic relations' (p. 71). For him, proper names do have meaning; they contribute to the meaning of the sentence in which they occur. However, the meaning is 'an isolated, unintegrated one, such that it cannot be related to the meanings of other words in terms of lexical relations' (Allerton, 1987, p. 71). Thus, for Allerton (1987), while names do not lack in connotations, the meaning is 'not integrated into the lexical and grammatical system of the language' (p. 81). In this way, proper names seem to exist both inside and outside of the lexicon (Allerton, 1987, p. 62).

For Van Langendonck (2007), 'sense' is meaningfulness, and so 'proper names are words just as others' (p. 67). In his view, names have associations or connotations (in the non-philosophical usage; that is, a feeling or idea that a word summons in a person, beyond its primary meaning) that arise from either the name's referent or from the name's phonological shape (Van Langendonck, 2007, p. 82). Van Langendonck (2007) suggests several different types of 'presuppositional meaning' that proper names can have: categorical (e.g. man, woman, country, city, month, etc.); associations (about the referent or from the word form) and connotations; emotive (interpreted personally or inherent in the name); and grammatical (gender, number, definiteness) (p. 86).

Neurolinguistic support for the notion that proper names have categorical meaning is found in Van Langendonck's (2007) reporting of German research done by Joseph Bayer on a patient with deep dyslexia (pp. 110-113). The patient could only access written text through the semantic route (i.e. processing via the lexicon), not the phonological route (i.e. written word to speech via phonemic processing). That is, when shown proper names, she could not read them but could recognise them as names and provide categorical information about them. For example, for personal names, she could usually specify whether the name denoted a man or woman. She identified place names as cities, countries or rivers. Bayer concluded that there must be 'a minimal lexical categorical sense belonging to the semantic memory' (Van Langendonck \& Van de Velde, 2016, p. 25). The patient could also provide connotative information about names. For example, Australia triggered the categorical information of 'country' but also connotations of 'far away' and 'kangaroos' (Van Langendonck, 2007).

An important consideration is how L2 readers glean sense or meaning from the proper names they meet. It may be that L2 readers analyse proper names differently than L1 readers. Lyons (1977) allows for the possibility that for language learners, the 'distinction between proper names and common nouns may not always be clear-cut, ... for example, ... when all the people called "Horace" are thought of as having one or more other properties by virtue of which the name "Horace" is peculiarly appropriate' (p. 220). This is relevant with respect to the assumption in L2 vocabulary and reading research, that L2 readers can easily identify and understand proper names they meet in continuous text. If an L2 reader's understanding of a given proper name is incomplete or incorrect, this may adversely affect comprehension.

\section{Lexicographical perspectives}

If proper names do have categorical and associative meaning, they can be treated as lexical items. Hanks (2013) remarks that from 'the point of view of corpus linguistics and computational linguists, [names] certainly are [words]' (p. 33). Shcherba (1940 [1995]), in his theory of lexicography, also asserts that names must have meaning because they are used in speech (p. 323). For him, names are words, albeit very different from common nouns, but that is not a reason to exclude them from the dictionary. The question is what meaning to assign names. Meaning is not of an encyclopaedic nature. Rather, Shcherba (1940 [1995]) says, 'The task is to define that necessary minimum without which it would be impossible to operate in a generally understandable way with a proper noun in speech' (p. 323). For example, if the proper name is a country name, then the fact that it is a country and not a person is the necessary information that one would need to understand to make sense of the 
name in a text. Shcherba (1940 [1995]) offers some examples of possible dictionary entries: 'Australia, "one of the countries of the world"; Louis XIV, "one of the French kings"' (p. 324). Furthermore, Shcherba (1940 [1995]) notes that not all names would need to be included in a dictionary, only those commonly known to a linguistic group (p. 324).

\section{Potential difficulties with proper names for L2 readers}

Different perspectives on proper names from philosophy, linguistics and lexicography include some less prevalent views that proper names have minimal lexical sense or meaning. Given this possibility that proper names represent lexical knowledge, it may be incautious to assume that L2 readers possess all the necessary information about the proper names they come across in texts. Such information may relate to, for example, category (i.e. whether the name refers to a place or person), or associations (e.g. Goldilocks). If L2 readers are unaware of this necessary information, it may negatively impact their reading comprehension. So, it is helpful to consider a few potential difficulties they might encounter with unfamiliar proper names.

One such difficulty concerns phonology. It has been suggested that there may be more plausible phonological sequences for names than for other words, thus making names more difficult to recall or learn (Brennen, 1993; James \& Fogler, 2007). In his plausible phonology hypothesis, Brennen (1993) suggests that learning of new phonology is done more often for names than it is for other words. He does not suggest that there are novel phonemes but rather novel sequences or syllables. Brennen (1993) argues that when one encounters a new proper name with a novel phonological sequence, the name essentially represents a new word to be learnt; this can make recall difficult. While he presents his hypothesis in the context of L1 users, it is worth considering this potential difficulty for L2 readers as well.

Another challenge concerns the use of context to infer information about an unfamiliar proper name. Some research that has found L2 readers may be less skilful at using syntactic and semantic information to infer word meaning than had been previously assumed (Bensoussan \& Laufer, 1984; Huckin \& Bloch, 1993; Nassaji, 2003). For example, Kobeleva (2012) found in her study that participants in the Names Unknown condition were able to derive less than $50 \%$ of necessary information about the proper name referent by relying on context. As Alderson (2000) notes,

Although context determines the meaning of an unknown word, it may not reveal it: revelation is limited not only by the explicitness of the connection between context and the unknown word, but also by the experience and skill of the reader. (p. 70)

Context might not always be available for the reader to draw on. In their vocabulary analysis of L1 school textbooks, Nagy and Anderson (1984) explain that some proper names, such as geographical names, are often not explained in context, and that lack of knowledge of such names would result in comprehension failure just as unfamiliarity with the meaning of any other word might.

There may also be a lack of transparency surrounding certain proper names for L2 readers, if clues from the L1 proper name equivalent are absent. To take an example from L2 vocabulary research, Horst (2013) states that some place names like the Arctic and Scotland are 'presumably transparent' for the target Arabic L2 readers of English in her paper (p. 174). However, there may in fact be a lack of transparency in such names for Arabic readers. For example, in Arabic, the Arctic is القطب الشمالي, pronounced as /alqutb alshamali/, and translates literally as the North Pole ('The Arctic', n.d.). Thus, there is no phonological clue for Arabic readers as to the meaning of Arctic, nor would the literal translation of the Arabic name be helpful as no mention is made of the North Pole in the example text given. This is not an exhaustive list of difficulties that L2 readers may have with unfamiliar names, but it does serve to illustrate that what may seem transparent or obvious to L1 readers with respect to proper names might not be as clear for L2 readers. 


\section{Conclusion}

While the prevailing view from philosophy and linguistics is that proper names do not have meaning (Mill, 1865; Lyons, 1977), and therefore constitute encyclopaedic knowledge, there is an alternative perspective that proper names have minimal lexical categorical meaning (Anderson, 2007; Van Langendonck, 2007). This is an important viewpoint to consider with respect to how L2 readers might respond to proper names: it may be the case that some L2 readers do analyse certain proper names in continuous text as lexis. But to assume that all proper names will be easily identified and understood by all $\mathrm{L} 2$ readers seems incautious.

There are implications for L2 reading and vocabulary research and pedagogy. As noted, the standard practice in L2 vocabulary research has been to treat proper names as known vocabulary (see Brown, 2010), and more recently, to remove proper names from lexical analysis altogether. However, when researchers and teachers start from a position that proper names are special kinds of words that are not always well understood, this might help create a more accurate picture of the L2 reader's lexical load. Rather than assuming names are known, a more cautious approach would be to categorise proper names in terms of frequency, as is done with other vocabulary in lexical analyses. Given that names are often culturally specific as well as ephemeral, many proper names will appear as 'off list', that is, not occurring in any of the frequency bands. Thus, when using this approach, certain proper names will have to be treated as UNKNOWN.

When researchers and teachers assume proper names are UNKNOWN, they are in a position to (re) consider potential difficulties inherent in each proper name for that particular target L2 reader group: What is the 'necessary minimum' required to operate with this name? Is there sufficient context to infer the necessary minimum? Does the L2 reader have a phonological representation of the name, helpful for ensuring retention in the working memory? What is the L1 equivalent for this name, if any? For example, the names Mary and Arachne would have very different processing loads for certain L2 readers, depending on several factors, including but not limited to their L1 and English learning experience.

As processors of a second language and culture, L2 readers will certainly encounter unfamiliar proper names. Hanks (2013) reports that, in some large lexical databases, aiming at full coverage of a language, over $70 \%$ of lexical entries already are proper names, and this percentage continues to increase' (pp. 35-36). This statistic is a powerful indicator that L2 readers will most definitely meet unfamiliar proper names in the target language. Further research into how L2 readers process these special kinds of words can serve to alert L2 reading teachers, material developers and assessment professionals to the potential difficulties with proper names.

\section{References}

Alderson, J. C. (2000). Assessing reading. Cambridge, UK: Cambridge University Press.

Allerton, D. J. (1987). The linguistic and sociolinguistic status of proper names: What are they, and who do they belong to? Journal of Pragmatics, 11, 61-92. doi:10.1016/0378-2166(87)90153-6.

Anderson, J. M. (2007). The grammar of names. Oxford, UK: Oxford University Press.

Bensoussan, M., \& Laufer, B. (1984). Lexical guessing in context in EFL comprehension. Journal of Research in Reading, 7(1), 15-32. doi:10.1111/j.1467-9817.1984.tb00252.x.

Brennen, T. (1993). The difficulty with recalling people's names: The plausible phonology hypothesis. Memory, 1(4), 409-431. doi:10.1080/09658219308258246.

Brown, D. (2010). An improper assumption? The treatment of proper nouns in text coverage counts. Reading in a Foreign Language, 22(2), 355-361.

Carver, R. (1994). Percentage of unknown vocabulary words in text as a function of the relative difficulty of the text: Implications for instruction. Journal of Reading Behavior, 26(4), 413-437. doi:10.1080/10862969409547861.

Coates, R. A. (2006). Properhood. Language, 82(2), 356-382. doi:10.1353/lan.2006.0084.

Frege, G. (1960). On sense and reference. In P. Geach \& M. Black (Eds.), Translations from the philosophical writings of Gottlob Frege (pp. 56-78). Oxford, UK: Blackwell.

Hanks, P. (2013). Lexical analysis: Norms and exploitations. Cambridge, UK: MIT Press. 
Hirsh, D., \& Nation, P. (1992). What vocabulary size is needed to read unsimplified texts for pleasure? Reading in a Foreign Language, 8(2), 689-696.

Horst, M. (2013). Mainstreaming second language vocabulary acquisition. The Canadian Journal of Applied Linguistics, 16(1), 171-188.

Hu, M. H., \& Nation, I. S. P. (2000). Unknown vocabulary density and reading comprehension. Reading in a Foreign Language, 13(1), 403-430.

Huckin, T., \& Bloch, J. (1993). Strategies for inferring word meaning in context: A cognitive model. In T. Huckin, M. Haynes, \& J. Coady (Eds.), Second language reading and vocabulary learning (pp. 153-176). Norwood, N.J.: Ablex Publishing Corp.

Hwang, K., \& Nation, I. S. P. (1989). Reducing the vocabulary load and encouraging vocabulary learning through reading newspapers. Reading in a Foreign Language, 6(1), 323-335.

James, L. E., \& Fogler, K. A. (2007). Meeting Mr Davis vs Mr Davin: Effects of name frequency on learning proper names in young and older adults. Memory, 15(4), 366-374. doi:10.1080/09658210701307077.

Kobeleva, P. (2012). Second language listening and unfamiliar proper names: Comprehension barrier? RELC Journal, 43(1), 83-98. doi:10.1177/0033688212440637.

Lyons, J. (1977). Semantics (Vol. 1). Cambridge, UK: Cambridge University Press.

Mill, J. S. (1865). A system of logic, ratiocinative and inductive (6th ed. Vol. 1). London, UK: Longmans, Green and Co.

Nagy, W. E., \& Anderson, R. C. (1984). How many words are there in printed school English? Reading Research Quarterly, 19 (3), 304-330. doi:10.2307/747823.

Nassaji, H. (2003). L2 vocabulary learning from context: Strategies, knowledge sources, and their relationship with success in L2 lexical inferencing. TESOL Quarterly, 37, 645-670. doi:10.2307/3588216.

Nation, I. S. P. (2006). How large a vocabulary size is needed for reading and listening? The Canadian Modern Language Review, 63, 59-82. doi:10.3138/cmlr.63.1.59.

Nation, I. S. P., \& Heatley, A. (2002). Range: A program for the analysis of vocabulary in texts [software]. Retrieved from http:// www.vuw.ac.nz/lals/staff/Paul_Nation.

Proper noun. (n.d.). In English Oxford Living Dictionaries. Retrieved from https://en.oxforddictionaries.com/definition/ proper_noun.

Shcherba, L. V. (1940 [1995]). Opyt obshchei teorii leksikografii. [Towards a general theory of lexicography]. International Journal of Lexicography, 8(4), 314-350.

Strawson, P. F. (1950). On referring. Mind, 59(235), 320-344.

The Arctic. (n.d.). In Google Translate. Retrieved from https://translate.google.com/

Uden, J., Schmitt, D., \& Schmitt, N. (2014). Jumping from the highest graded readers to ungraded novels: Four case studies. Reading in a Foreign Language, 26(1), 1-28.

Van Langendonck, W. (2007). Theory and typology of proper names. Berlin, Germany: Mouton de Gruyter.

Van Langendonck, W., \& Van de Velde, M. (2016). Names and grammar. In C. Hough (Ed.), The Oxford handbook of names and naming (pp. 17-38). Oxford, UK: Oxford University Press.

Webb, S., \& Macalister, J. (2013). Is text written for children useful for L2 extensive reading? TESOL Quarterly, 47(2), 300-322. doi:10.1002/tesq.70.

Webb, S., \& Rodgers, M. P. H. (2009). Vocabulary demands of television programs. Language Learning, 59, 335-366. doi:10.1111/j.1467-9922.2009.00509.x.

Kimberly Klassen completed her PhD in applied linguistics (lexical studies) at Cardiff University, Wales. She is currently an instructor in the English for Liberal Arts program at the International Christian University, Tokyo, Japan. Her research interests include second language reading and vocabulary acquisition. Recent publications have appeared in Reading Psychology and The Curriculum Journal. She has taught English as a foreign language in Korea, Taiwan, the United Arab Emirates and Japan.

Cite this article: Klassen, K. (2022). Proper name theory and implications for second language reading. Language Teaching, 55(2), 149-155. https://doi.org/10.1017/S026144482100015X 